\title{
MODIFIKASI ALGORITMA WELCH-POWELL UNTUK OPTIMALISASI PENJADWALAN UJIAN SKRIPSI
}

\author{
Koko Harianto \\ Teknik Informatika, STMIK Amik Riau \\ Jl. Purwodadi Indah, km.10 Panam - Pekanbaru \\ E-Mail : kokoharianto@stmik-amik-riau.ac.id
}

\begin{abstract}
ABSTRAK
Penjadwalan ujian skripsi bagi mahasiswa tahap akhir adalah salah satu persoalan yang memerlukan perhatian khusus bagi pejabat pembuat jadwal. Hal yang serupa juga menjadi perhatian di Jurusan Teknik Informatika Sekolah Tinggi Manajemen Informatika dan Komputer Amik Riau (STMIK Amik Riau). Penelitian penjadwalan ujian skripsi telah dilakukan di STMIK Amik Riau dengan memanfaatkan teknik pewarnaan simpul graf pada algoritma Welch-Powell. Namun pemanfaatan algoritama tersebut belum maksimal, dimana masih diperlukan administrator untuk melakukan validasi ulang terhadap jadwal yang telah diolah menggunakan algoritma tersebut. Berdasarkan hal tersebut, maka dirasa perlu untuk melanjutkan penelitian terdahulu untuk menyelesaikan persoalan-persoalan yang masih ditemukan sehingga aplikasi penjadwalan ujian skripsi dapat terbentuk tanpa ditemukan lagi jadwal ujian yang saling tumpeng tindih. Penelitian ini masih menggunakan algoritma WelchPowell, namun dilakukan modifikasi untuk memaksimalkan kemampuan algoritma berdasarkan kebutuhan penjadwalan ujian skripsi yang ada di Jurusan Teknik Informatika STMIK Amik Riau. Analisa dan pengujian yang telah dilakukan terhadap 10 data peserta ujian memberikan hasil bahwa sebanyak sepuluh mahasiswa dapat ujian secara bersamaan yang terbagi kedalam 4 kelompok ujian. Artinya untuk 10 orang mahasiswa tersebut, pihak pembuat jadwal ujian cukup menentukan 4 waktu ujian saja, tanpa ada lagi ujian yang tumpang tindih baik berdasarkan dosen pembimbing maupun dosen penguji.
\end{abstract}

Kata Kunci: modifikasi, algoritma Welch-Powel, Ujian Skripsi, STMIK Amik Riau

\begin{abstract}
Scheduling thesis examination for students of the final stage is one of the issues that require special attention. Something similar is also a concern in the Department of Information STMIK Amik Riau. Scheduling research thesis examination has been conducted in STMIK Amik Riau (computer college) by using the graph vertex coloring techniques at Welch-Powell algorithm. However, algoritama utilization is not maximized, cause still required the administrator to re-validate against a schedule that has been processed using the algorithm. Based on that, it is felt necessary to continue previous research to resolve the issues that still found so that the thesis examination scheduling applications can be formed. This research is still using the Welch-Powell algorithm, however be modified to maximize the ability of an algorithm based on thesis examination requirements in the Department of Informatics STMIK Amik Riau. Analysis and testing that has been performed on 10, showed that data examinees provide results that as many as ten students can simultaneously test were divided into four test groups. This means that for the 10 students, the exam schedule maker just set four time of thesis examination, without any schedule that overlap either by lecturers or examiners.
\end{abstract}

Keyword: Modification, Welch-Powell algorithm, Thesis Examination, STMIK Amik Riau

\section{PENDAHULUAN}

Penjadwalan peserta ujian skripsi di STMIK Amik Riau merupakan salah satu persoalan mendasar yang harus diselesaikan. Penelitian sebelumnya yang telah dituangkan dalam jurnal SATIN (2015) oleh Koko Harianto dan T.Sy.Eiva Fatdha dengan judul Penerapan Pewarnaan Simpul Graf untuk Menenentukan Jadwal Ujian Skripsi pada STMIK Amik Riau Menggunakan Algoritma Welch-Powell telah memberikan kesimpulan 
bahwa teknik pewarnaan simpul graf dengan menggunakan algoritma Welch-Powell dapat diterapkan untuk membentuk jadwal ujian skripsi di STMIK Amik Riau, sehingga sistem penjadwalan ujian skripsi yang dibentuk dapat menghasilkan jadwal ujian skripsi yang terhindar dari tumpang tindih waktu pelaksanaan. Hal yang sama juga telah dilakukan oleh Imelda Lumbantoruan (2014) yang menerapkan algoritma Welch-Powell untuk penyusunan jadwal bimbingan belajar yang optimal, kemudian Agus Susiloputro et al menggunakan algoritma yang sama untuk penyelesaian penjadwalan ujian akhir semester.

Penelitian ini merupakan penelitian lanjutan dari penelitian yang telah diterbitkan pada jurnal SATIN tentang pemanfaatan algoritma Welch-Powell. Pada peneitian sebelumnya masih membutuhkan administrator yang bertugas untuk melakukan validasi terhadap jadwal yang dibuat oleh sistem, jika masih terdapat jadwal yang tumpang tindih, maka administrator akan mengatur kembali.

Berdasarkan kekurangan tersebut, maka dianggap perlu untuk melakukan penelitian lanjutan sehingga tidak lagi diperlukan administrator untuk melakukan validasi setiap tahapan algortima.

\section{Teori Graf}

Suatu graf $G$ terdiri dari dua himpunan yaitu himpunan $\mathrm{V}$ dan himpunan E. V (Vertex) merupakan himpunan simpul yang terbatas dan tidak kosong, sedangkan $\mathrm{E}$ (Edge) merupakan himpunan busur yang menghubungkan sepasang simpul. Simpul graf dapat merupakan objek seperti kota, lampu lalu lintas, rumah, dan sebagainya. Busur dapat menunjukkan hubungan (relasi) sembarang seperti jalan raya, sambungan DOI : https://doi.org/10.36341/rabit.v2i1.146 telepon, dan lain-lain. Notasi graf adalah $\mathrm{G}(\mathrm{V}, \mathrm{E})$ artinya graf $\mathrm{G}$ memiliki $V$ simpul dan E busur (Riwinoto, R. Yogo Kartono Isal, 2010). Graf $\mathrm{G}$ adalah pasangan $(\mathrm{V}(\mathrm{G})$, $\mathrm{E}(\mathrm{G})$ ), dimana $\mathrm{V}(\mathrm{G})$ adalah himpunan berhingga tidak kosong, yang elemenelemennya disebut simpul (vertek), dan $\mathrm{E}(\mathrm{G})$ adalah himpunan pasangan- pasangan tak berurut dari elemen- elemen $\mathrm{V}(\mathrm{G})$ yang berbeda disebut sisi (edge) (Rahmat Januar Noor, Hasmawati dan Hendra,2013).

Menurut Rinaldi Munir, secara matematis, graf didefinisikan sebagai pasangan himpunan $(\mathrm{V}, \mathrm{E})$, ditulis dengan notasi $\mathrm{G}=(\mathrm{V}, \mathrm{E})$, yang dalam hal ini $\mathrm{V}$ adalah himpunan tidak kosong dari simpulsimpul (vertices atau node) dan E adalah himpunan sisi (edge atau arc) yang menghubungkan sepasang simpul, himpunan E boleh kosong. Sebuah graf dimungkinkan tidak mempunyai sisi satu buah pun, tetapi simpulnya harus ada, minimal satu. Graf yang hanya mempunyai satu buah simpul tanpa sebuah sisi pun dinamakan graf trivial. Simpul pada graf dapat dinomori dengan huruf, bilangan asli ataupun gabungan keduanya (Rinaldi Munir,2012).

\section{Algoritma Welch-Powell}

Menurut Rinaldi Munir Algoritma Welch-Powell dapat digunakan untuk mewarnai sebuah graf $G$ secara mangkus atau efektif. Adapun algoritma welch-powell adalah (Rinaldi Munir,2012):

1. Urutkan simpul-simpul dari $G$ dalam derajat yang menurun.

2. Gunakan satu warna untuk mewarnai simpul pertama (yang mempunyai derajat tertinggi) dan simpul-simpul lain (dalam urutan yang berurut) yang tidak bertetangga dengan simpul pertama ini. 
3. Mulai lagi dengan simpul derajat tertinggi berikutnya di dalam daftar terurut yang belum diwarnai dan ulangi proses pewarnaan simpul dengan menggunakan warna kedua.

4. Ulangi penambahan warna-warna sampai semua simpul telah diwarnai.

\section{Penjadwalan Ujian Skripsi}

Penjadwalan merupakan alokasi dari sumber daya terhadap waktu untuk menghasilkan sebuah kumpulan pekerjaan (Dedi Masyoyo, 2014). Penyelesaian kasus penjadwalan pada hakikatnya adalah berupaya untuk mengalokasikan sejumlah aktifitas yang mengandung constraint atau batasan ke dalam timeslot (matriks ruang dan waktu). Jumlah timeslot yang tersedia juga memiliki batasan, baik berupa maupun waktu penggunaannya. Oleh karena itu, penjadwalan yang baik haruslah dapat menyesuaikan sejumlah keterbatasan resource atau sumber daya yang ada agar seluruh aktifitas dapat tetap terlaksana tanpa melanggar constraint-nya. Pewarnaan graf mengakomodasi hal tersebut dengan bilangan kromatik (Setia Astuti, 2011).

Penjadwalan adalah suatu proses pengalokasian sumber daya yang ada untuk menghasilkan suatu jadwal yang teratur dan sesuai dengan permintaan. Pada penelitian in penjadwalan ujian skripsi dimaksudkan untuk membentuk jadwal ujian skripsi oleh mahasiswa agar tidak lagi ditemukan jadwal ujian yang tumpang tindih (Koko Harianto dan T. Sy. Eiva Fatdha, 2015). penelitian sebelumnya. Penggunaan data yang sama dimaksudkan agar terlihat perbedaan penelitian ini dengan penelitian sebelumnya. Data yang digunakan adalah data 10 (sepuluh) orang peserta ujian skripsi mahasiswa STMIK Amik Riau.

Tabel 1. Data Peserta

\begin{tabular}{|c|c|c|c|}
\hline $\begin{array}{c}\text { No } \\
\text { · }\end{array}$ & NIM & $\begin{array}{c}\text { Nama } \\
\text { Mahasisw } \\
\text { a }\end{array}$ & $\begin{array}{l}\text { Dewan } \\
\text { Penguji }\end{array}$ \\
\hline 1. & $\begin{array}{c}.10 .031 \\
802.20 \\
4\end{array}$ & Nurdin & $\begin{array}{ll}\text { 1. Edwar Ali, } & \text { M.Kom } \\
\text { 2. Rahmiati, } \\
\text { M.Kom } \\
\text { 3. Hamdani, } \\
\text { M.Kom }\end{array}$ \\
\hline 2. & $\begin{array}{c}.10 .031 . \\
802.18 \\
5\end{array}$ & $\begin{array}{r}\text { Muhamma } \\
\text { d Jamaris }\end{array}$ & $\begin{array}{ll}\text { 1. Nurjayadi, } \\
\text { M.Kom } \\
\text { 2. Rahmadde } \\
\text { ni, M.Kom } \\
\text { 3. Herwin, } \\
\text { M.Kom }\end{array}$ \\
\hline 3. & $\begin{array}{c}.10 .031 \\
802.03 \\
4\end{array}$ & $\begin{array}{c}\text { Andri } \\
\text { Wahyudi }\end{array}$ & $\begin{array}{l}\text { 1. Rahmiati, } \\
\text { M.Kom } \\
\text { 2. T.Sy. Eiva } \\
\text { Fatdha, } \\
\text { M.Kom } \\
\text { 3. Nurjayadi, } \\
\text { M.Kom }\end{array}$ \\
\hline 4. & $\begin{array}{c}.10 .031 \\
802.21 \\
9\end{array}$ & $\begin{array}{l}\text { Rispi } \\
\text { Rianto }\end{array}$ & $\begin{array}{ll}\text { 1. Helda } \\
\text { Yenni, } \\
\text { M.Kom } \\
\text { 2. Susandri, } \\
\text { M.Kom } \\
\text { 3. Fransiskus } \\
\text { Zoromi, } \\
\text { S.Kom }\end{array}$ \\
\hline 5. & $\begin{array}{c}.10 .031 . \\
802.16 \\
0\end{array}$ & $\begin{array}{c}\text { M. Khairul } \\
\text { Anam }\end{array}$ & $\begin{array}{l}\text { 1. Triyani } \\
\text { Arita Fitri, } \\
\text { M.Kom }\end{array}$ \\
\hline
\end{tabular}

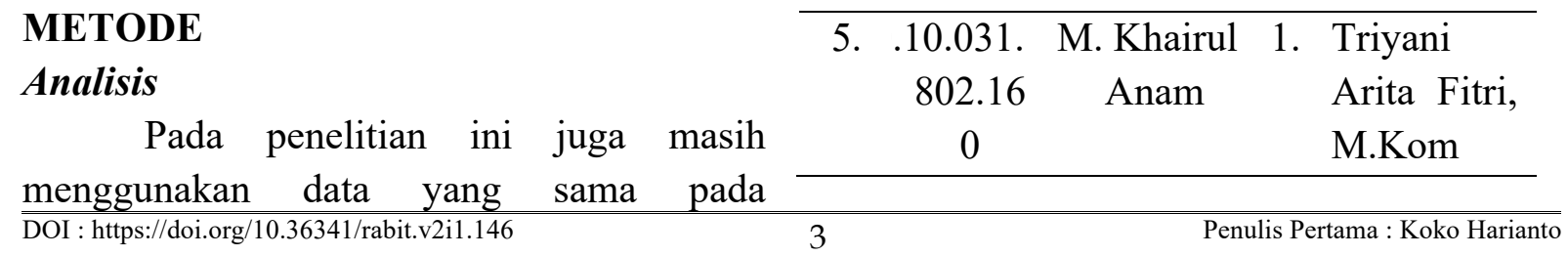




\section{RABIT : Jurnal Teknologi dan Sistem Informasi Univrab}

Volume 2 No. 1 | Januari 2017 : 1-11

2. Rahmadde ni, M.Kom

3. Rahmiati, M.Kom

\begin{tabular}{|c|c|c|c|}
\hline 6. & $\begin{array}{c}.10 .031 \\
802.26 \\
6\end{array}$ & Suwarso & $\begin{array}{l}\text { 1. Tashid, } \\
\text { M.Kom } \\
\text { 2. Torkis } \\
\text { Nasution, } \\
\text { M.Kom } \\
\text { 3. Wirta } \\
\text { Agustin, } \\
\text { M.Kom }\end{array}$ \\
\hline 7. & $\begin{array}{c}.10 .031 \\
802.28 \\
0\end{array}$ & $\begin{array}{l}\text { Tarya } \\
\text { Liyanti }\end{array}$ & $\begin{array}{l}\text { 1. Edwar Ali, } \\
\text { M.Kom } \\
\text { 2. Triyani } \\
\text { Arita Fitri, } \\
\text { M.Kom } \\
\text { 3. Tashid, } \\
\text { M.Kom }\end{array}$ \\
\hline 8. & $\begin{array}{c}.10 .031 \\
802.36 \\
1\end{array}$ & Toy Iman & $\begin{array}{l}\text { 1. Edwar Ali, } \\
\text { M.Kom } \\
\text { 2. Tashid, } \\
\text { M.Kom } \\
\text { 3. Hamdani, } \\
\text { M.Kom }\end{array}$ \\
\hline
\end{tabular}

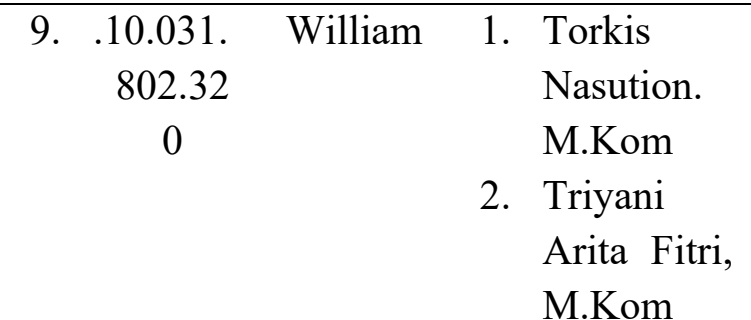

3. Dwi

Haryono, M.Kom

\begin{tabular}{|c|c|c|}
\hline $\begin{array}{c}10.031 \\
802.07 \\
6\end{array}$ & $\begin{array}{c}\text { Didik } \\
\text { Sudyana }\end{array}$ & $\begin{array}{ll}\text { 1. } & \text { Herwin, } \\
\text { M.Kom } \\
\text { 2. Edwar Ali, } \\
\text { M.Kom } \\
\text { 3. Fransiskus } \\
\text { Zoromi, } \\
\text { S.Kom }\end{array}$ \\
\hline
\end{tabular}

Selanjutnya adalah membuat datadata tersebut menjadi sebuah graf. Setiap data akan diwakili oleh sebuah vertex (titik) seperti berikut.

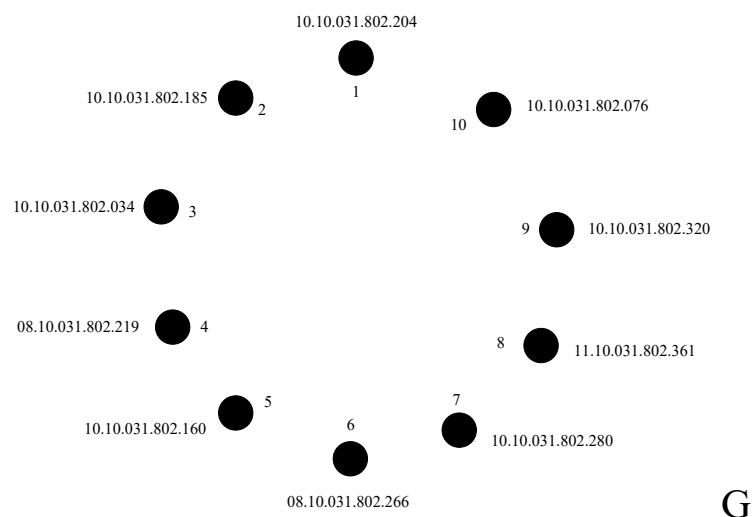

ambar 1. Konversi Data Peserta Ujian Menjadi Titik (vertex) Graf

Selanjutnya adalah memberikan garis (edge) yang menghubungkan masing-masing titik. Dalam hal ini apabila satu mahasiswa memiliki minimal satu orang dosen pembimbing ataupun penguji yang sama dengan mahasiswa lainnya, maka antara titik tersebut memiliki garis lurus yang menghubungkan keduanya.

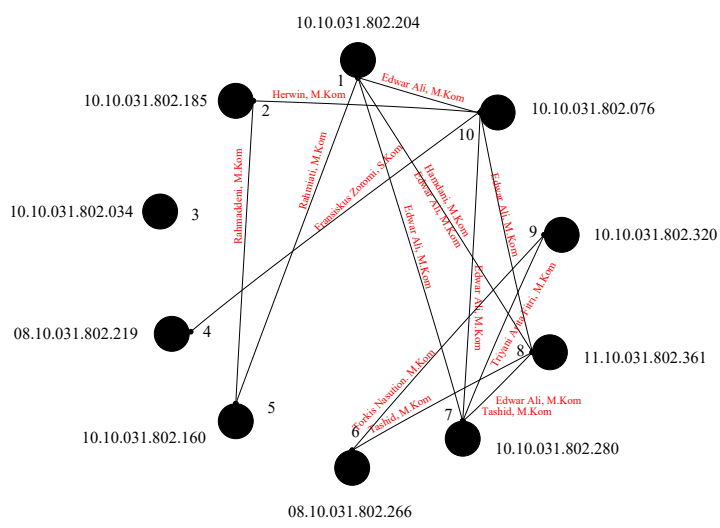

Gambar 2. Graf Peserta Ujian

Setelah pemberian garis selesai, maka selanjutnya adalah menerapkan algoritma Welch-Powell. 


\section{Analisa Data menggunakan}

\section{Algoritma Welch-Powell}

Setelah dilakukannya analisa terhadap data, maka selanjutnya adala analisa data terhadap algoritma yang akan digunakan untuk memberikan warna simpul graf. Sebelum menerapkan algoritma Welchpowell untuk memberikan warna simpul graf, terlebih dahulu melakukan perhitungan jumlah derajat masing-masing simpul kemudian simpul disusun terurut berdasarkan jumlah derajat tertinggi. Urutan simpul pada graf di atas akan diperlihatkan pada tabel berikut.

Tabel 2. Urutan Simpul Graf Data Analisa

\begin{tabular}{|c|c|c|}
\hline Simpul & Simpul Relasinya & $\begin{array}{c}\text { Jumlah } \\
\text { Deraj } \\
\text { at }\end{array}$ \\
\hline 10.10 .031 .802 .076 & $\begin{array}{l}10.10 .031 .802 .204 \\
10.10 .031 .802 .280 \\
11.10 .031 .802 .361 \\
08.10 .031 .802 .219 \\
10.10 .031 .802 .185\end{array}$ & 5 \\
\hline 10.10 .031 .802 .204 & $\begin{array}{l}10.10 .031 .802 .160 \\
10.10 .031 .802 .076 \\
10.10 .031 .802 .280 \\
11.10 .031 .802 .361\end{array}$ & 4 \\
\hline 10.10 .031 .802 .280 & $\begin{array}{l}10.10 .031 .802 .320, \\
10.10 .031 .802 .076 \\
10.10 .031 .802 .204, \\
11.10 .031 .802 .361\end{array}$ & 4 \\
\hline 11.10 .031 .802 .361 & $\begin{array}{l}08.10 .031 .802 .266, \\
10.10 .031 .802 .076, \\
10.10 .031 .802 .204, \\
10.10 .031 .802 .280\end{array}$ & 4 \\
\hline 08.10 .031 .802 .266 & $\begin{array}{l}10.10 .031 .802 .320 \\
11.10 .031 .802 .361\end{array}$ & 2 \\
\hline 10.10 .031 .802 .160 & $\begin{array}{c}10.10 .031 .802 .185 \\
10.10 .031 .802 .204\end{array}$ & 2 \\
\hline 10.10 .031 .802 .185 & $\begin{array}{c}10.10 .031 .802 .160 \\
10.10 .031 .802 .076\end{array}$ & 2 \\
\hline
\end{tabular}

\begin{tabular}{ccc}
\hline 10.10 .031 .802 .320 & $\begin{array}{l}10.10 .031 .802 .280, \\
08.10 .031 .802 .266\end{array}$ & 2 \\
& 08.10 .10 .031 .802 .076 & 1 \\
\hline 08.10 .031 .802 .219 & - & \\
\hline 10.10 .031 .802 .034 & - & \\
\hline
\end{tabular}

Setelah semua simpul terurut berdasarkan jumlah simpul tertinggi, selanjutnya menerapkan algoritma Welchpowell untuk menentukan warna masingmasing simpul. Terlebih dahulu berikan warna pertama (misalnya kuning) pada simpul "10.10.031.802.076", karena simpul tersebut merupakan simpul dengan jumlah derajat tertingi. Selanjutnya berikan juga warna yang sama untuk semua simpul lainnya yang tidak terhubung terhadap simpul "10.10.031.802.076". Berikut ini merupakan gambaran dari warna simpul yang dihasilkan untuk simpul "10.10.031.802.076" serta simpul lainnya yang dibolehkan memiliki warna yang sama.

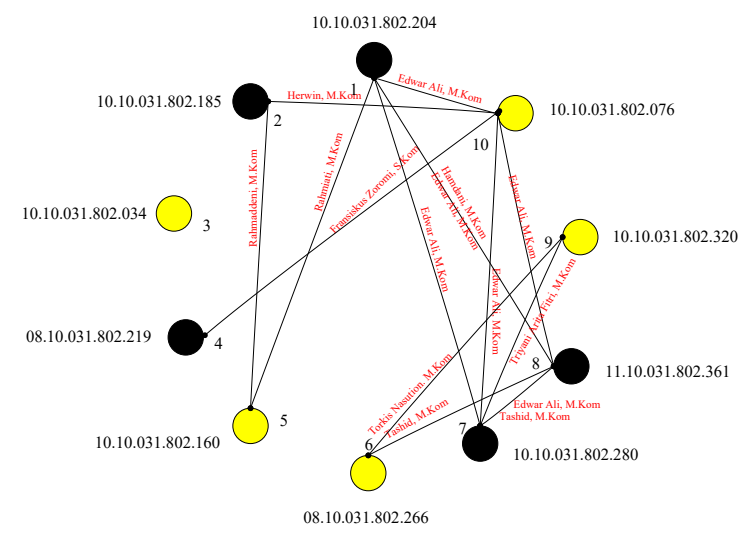

Gambar 3. Pemberian Warna Pertama

Gambar di atas yang merupakan hasil pemberian warna pertama menggunakan algoritma Welch-powell yang memberikan solusi bahwa ada 4 (empat) simpul lainnya yang diperbolehkan memiliki warna yang sama dengan simpul "10.10.031.802.076" karena 4 (empat) simpul lainnya tersebut tidak terhubung dengan simpul “10.10.031.802.076”. Namun jika 
diperhatikan dengan cermat terdapat kesalahan untuk simpul "08.10.031.802.266" dan simpul "10.10.031.802.320" seperti yang terlihat pada gambar 4.7. Kedua simpul tersebut tidak terhubung dengan "10.10.031.802.076", namun keduanya saling terhubung sehingga akan terjadi kesalahan jika keduanya diberikan warna yang sama.

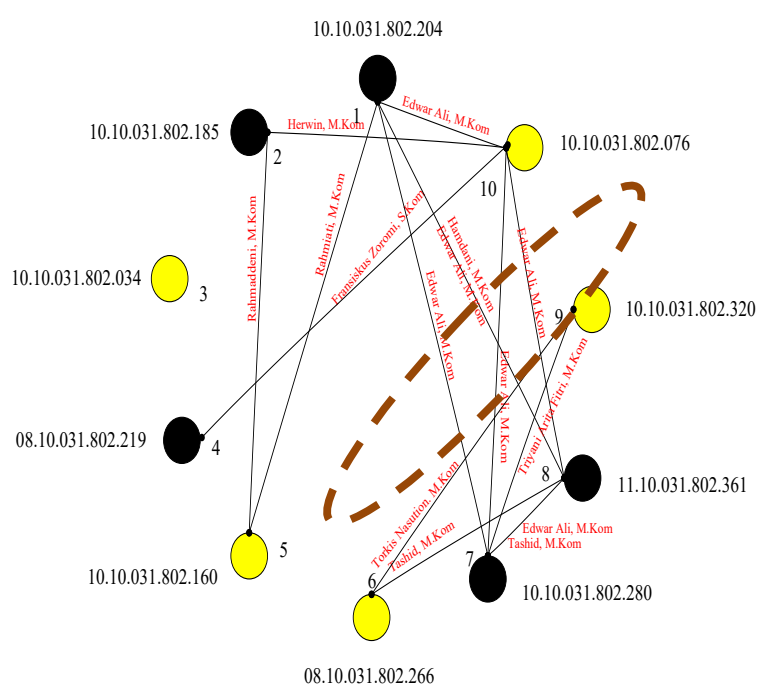

Gambar 4. Pemberian Gambar Kedua

Pada tahapan analisa ini penulis menemukan kelemahan dari algoritma Welch-powell, sehingga penulis menyimpulkan algoritma Welch-powell secara sederhana tidak dapat menyelesaikan permasalahan bentrok jadwal, sehingga agar algoritma dapat digunakan, maka perlu dilakukannya modifikasi terhadap algoritma Welch-powell. Proses modifikasi algoritma hingga cara menggunakannya akan diulas pada tahapan perancangan.

\section{HASIL}

\section{Modifikasi Algoritma Welch-Powell}

Modifikasi algoritma Welch-powell dimaksudkan untuk menyelesaikan persoalan yang ditemukan pada tahapan analisa. Algoritma yang akan diterapkan nantinya merupakan algoritma hasil modifikasi oleh penulis bardasarkan algoritma Welch-powell. Adapun algoritma yang telah dimodifikasi adalah:

1. Urutkan simpul-simpul dari $G$ dalam derajat yang menurun.

2. Gunakan satu warna untuk mewarnai simpul pertama (yang mempunyai derajat tertinggi) dan simpul-simpul lain (dalam urutan derajat yang tertinggi) yang tidak bertetangga dengan simpul pertama ini.

3. Cek untuk seluruh simpul dalam warna yang sama. Jika ditemukan simpul yang saling terhubung, maka hilangkan warna dari salah satu simpul yang saling terhubung.

4. Mulai lagi dengan simpul derajat tertinggi berikutnya di dalam daftar terurut yang belum diwarnai dan ulangi proses pewarnaan simpul dengan menggunakan warna kedua.

5. Ulangi penambahan warna-warna sampai semua simpul telah diwarnai.

Untuk dapat melihat perbedaan terhadap algoritma Welch-powell dengan algoritma Welch-powell yang telah dimodifikai, maka penulis membuat 2 (dua) bagan alir (flowchart). 


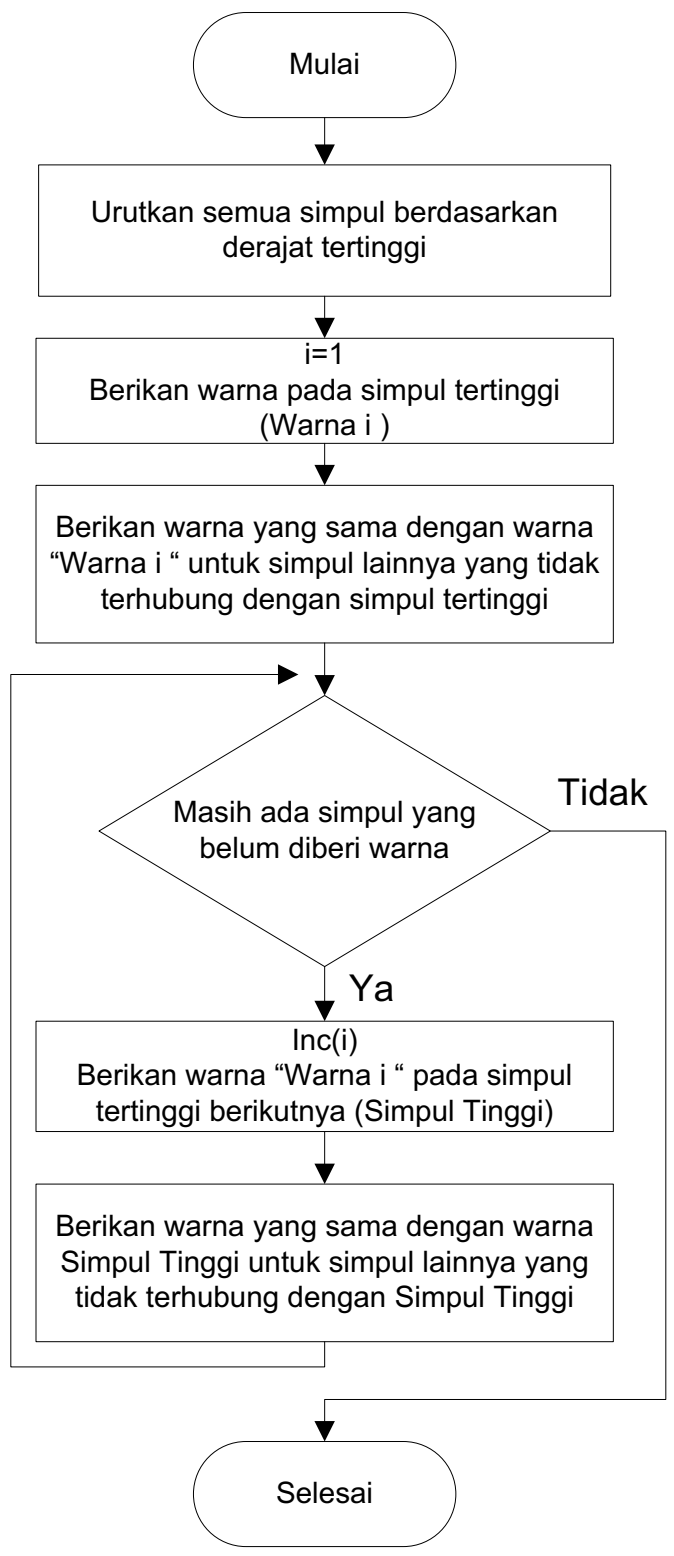

Gambar 5. Algoritma Welch-Powell

Bagan alir di atas merupakan bagan alir untuk algoritma Welch-powell yang belum dimodifikasi. Dengan dilakukannya modifikasi algoritma seperti yang telah dielaskan pada poin 4.2.1, maka selanjutnya dibentuk sebuah bagan alir untuk algoritma Welch-powel yang telah dimodifikasi. Pembuatan bagan alir dimaksudkan sebagai alat bantu dalam pembuatan program.

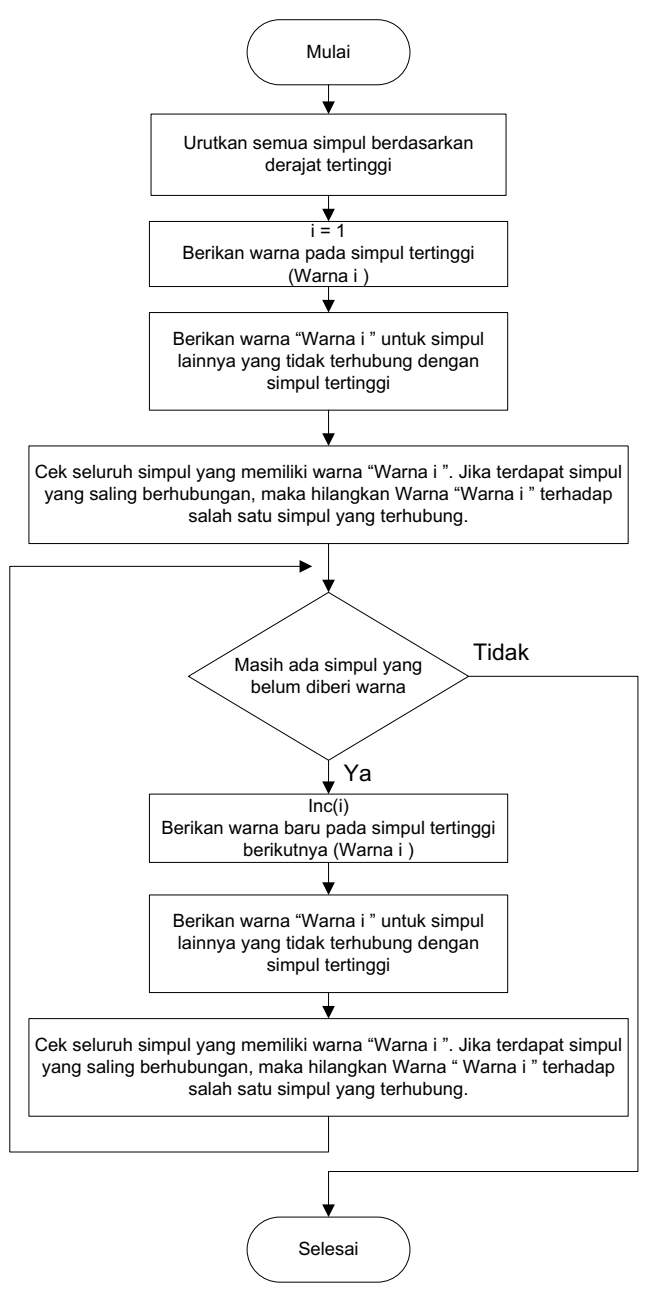

Gambar 6. Algoritma Welch-Powell yang telah Dimodifikasi

\section{Penerapan Algoritma yang Telah Dimodifikasi}

Modifikasi yang penulis lakukan terletak pada poin 3 (tiga). Dengan menerapkan algoritma modifikasi tersebut, maka simpul "10.10.031.802.320" dilepaskan dari warna kuning seperti terlihat pada gambar berikut. 


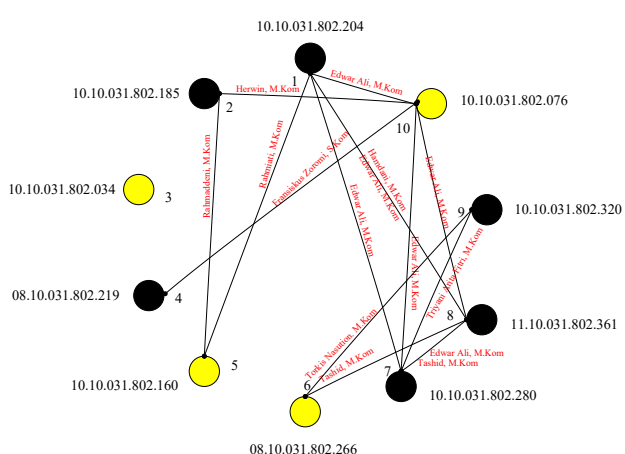

Gambar 7. Menghilangkan Bentrok Warna

Selanjutnya adalah memberikan warna kedua terhadap graf (misalnya warna biru). Simpul tertinggi berikutnya yang belum diwarnai adalah simpul "10.10.031.802.204", sehingga simpul tersebut akan diberikan warna biru beserta seluruh simpul-simpul lainnya yang belum memiliki warna dan tidak terhubung dengan simpul “10.10.031.802.204". Adapun simpul-simpul yang diperbolehkan memiliki warna yang sama dengan simpul "10.10.031.802.204" adalah simpul "10.10.031.802.185", simpul "10.10.031.802.320", dan simpul “08.10.031.802.219" seperti yang diperlihatkan pada gambar berikut.

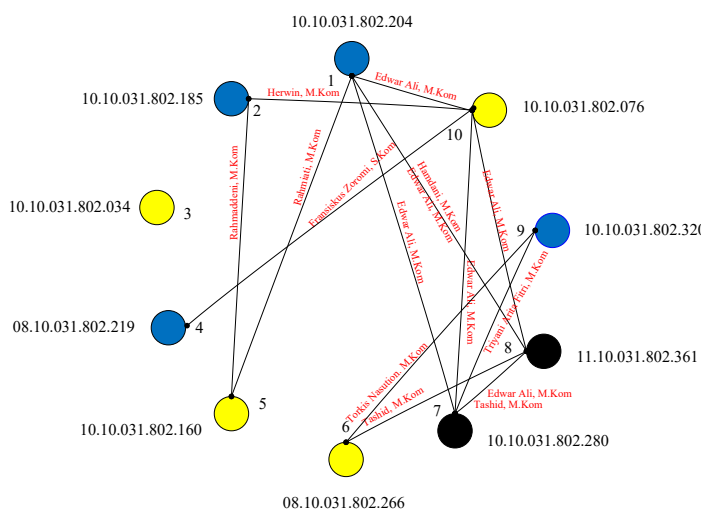

Gambar 8. Pemberian Warna Kedua

Pada gambar di atas tidak ditemukan permasalahan pada pemberian warna kedua, sehingga dapat dilanjutkan dengan pemberian warna ketiga. Pemberian warna ketiga dilakukan terhadap simpul yang memiliki derajat tertinggi berikutnya yaitu simpul "10.10.031.802.280" beserta simpulsimpul lainnya yang belum diberi warna serta tidak terhubung dengan simpul “10.10.031.802.280". Pada graf tersebut hanya tersisa 1 simpul lainnya yaitu simpul "11.10.031.802.361", namun simpul "11.10.031.802.361" terhubung dengan simpul “10.10.031.802.280” sehingga kedua simpul tersebut harus memiliki warna yang berbeda seperti yang ditunjukkan oleh gambar berikut.

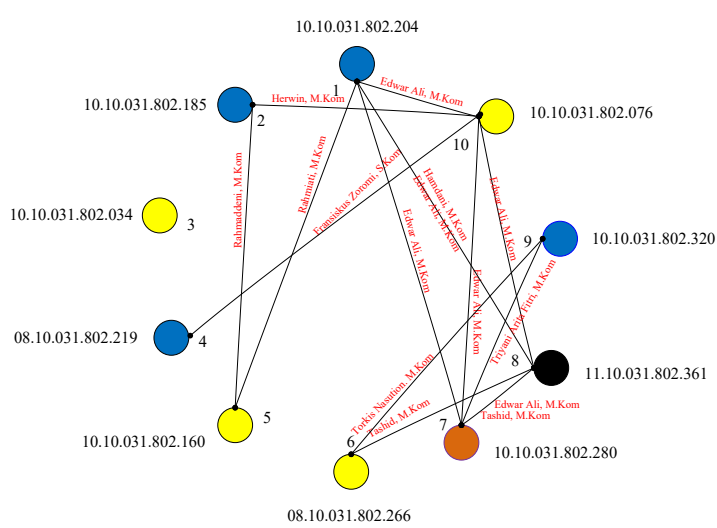

Gambar 9. Pemberian Warna Ketiga

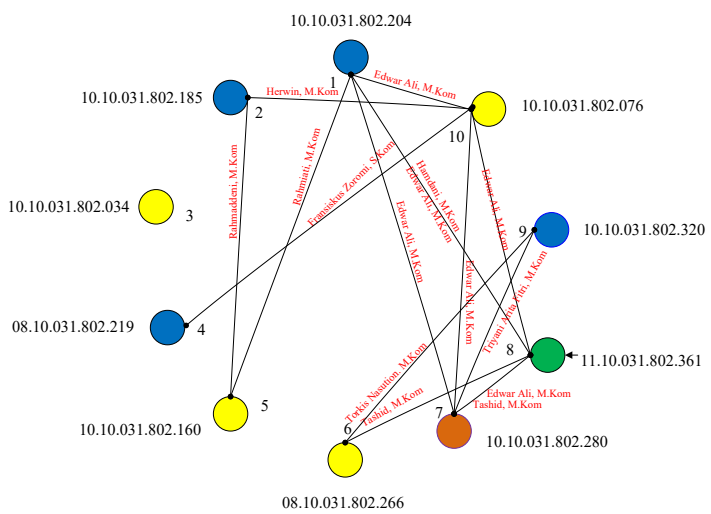

Gambar 10. Pemberian Warna Keempat

\section{Pembentukan Kelompok Ujian}

Dengan selesainya proses pemberian warna simpul yang diperlihatkan pada 
gambar di atas, maka proses pembentukan jadwal terhadap 10 mahasiswa tersebut telah selesai. Tahapan selanjutnya adalah mengelompokkan peserta ujian berdasarkan warna simpul. Berdasarkan warna simpul yang dihasilkan, maka diperoleh jadwal ujian skripsi sebanyak 4 (empat) kelompok ujian seperti yang diperlihatkan pada tabel berikut.

Tabel 3. Daftar Kelompok Ujian

\begin{tabular}{ccl}
\hline $\begin{array}{c}\text { Kelompok } \\
\text { Ujian Ke- }\end{array}$ & NIM & $\begin{array}{l}\text { Warna } \\
\text { Simpul }\end{array}$ \\
\hline & 10.10 .031 .802 .076 & \\
1 & 08.10 .031 .802 .266 & Kuning \\
& 10.10 .031 .802 .160 & \\
& 10.10 .031 .802 .034 & \\
\hline & 10.10 .031 .802 .204 & \\
2 & 10.10 .031 .802 .185 & Biru \\
& 10.10 .031 .802 .320 & \\
\hline 3 & 08.10 .031 .802 .219 & \\
\hline 4 & 10.10 .031 .802 .280 & Cokelat \\
\hline
\end{tabular}

Proses pembentukan jadwal ujian menggunakan algoritma Welch-powell yang telah dimodifikasi memberikan hasil yang baik seperti yang terlihat pada gambar. Namun representasi jadwal dalam bentuk visual seperti yang terlihat pada gambar akan membutuhkan tingkat ketelitian yang tinggi jika data yang digunakan semakin banyak. Ketelitian sangat dibutuhkan untuk melihat realasi-relasi simpul dengan benar, hal ini dikarenakan semakin banyak simpul, maka semakin rapat jarak antar simpul serta dimungkinkan semakin banyak relasi yang dihasilkan sehingga semakin banyak garis yang saling berpotongan dan bahkan berhimpitan.

Untuk mengatasi hal tersebut, maka digunakan kemampuan komputer untuk membentuk jadwal dengan algoritma Welch- powell yang sudah dimodifikasi. Komputer akan bekerja selayaknya menyusun simpulsimpul serta menarik garis relasi tiap-tiap simpul, namun proses tersebut tidak di tampilkan dalam bentuk visual, melainkan dalam bentuk tabel.

\section{Implementasi Program}

Sebelumnya telah dijelaskan bahwa proses menentukan simpul-simpul yang tidak berhubungan serta memberikan warna masing-masing simpul guna membentuk jadwal ujian skripsi yang dilakukan secara visual akan membutuhkan ketelitian yang tinggi, sehingga diperlukan kemampuan komputer untuk melakukannya. Pada penelitian ini, komputer akan membentuk jadwal ujian skripsi berdasarkan bagan alir yang telah dirancang. Tahap awal adalah mendaftarkan seluruh peserta ujian ke sistem.

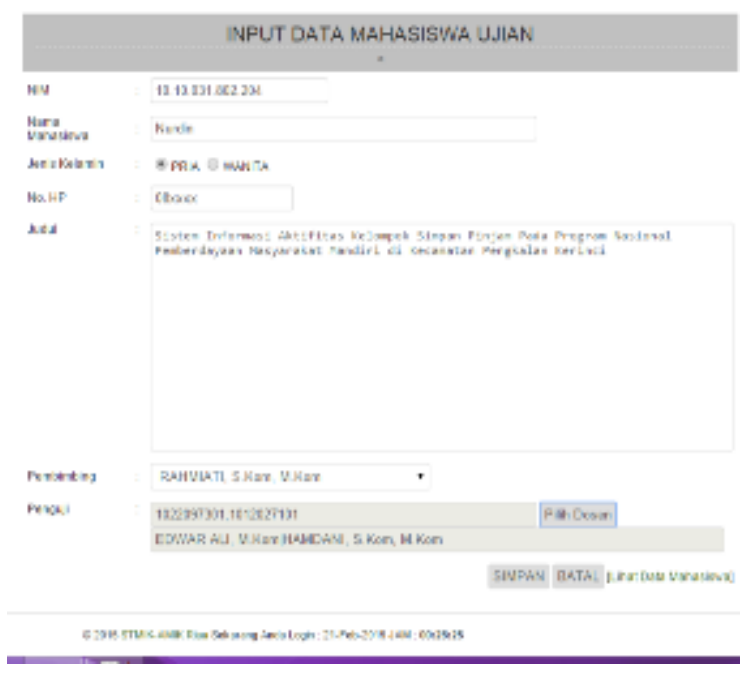

Gambar 11. Form Input Data

Selanjutnya adalah membentuk jadwal terhadal 10 data mahasiswa beserta seluruh dosen pembimbing dan pengujinya, sehingga sistem akan membuat kelompok ujian 
berdasarkan algoritma Welch-Powell yang telah dimodifikasi.

\section{SISTEM RENJADWALAN}

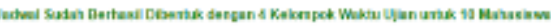

Gambar 12. Tampilan Penerapan Algoritma Welch-Powell

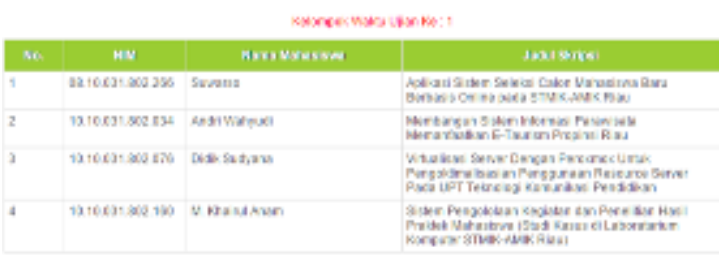

Gambar 13. Kelompok Waktu Ujian Ke-1 untuk 10 Mahasiswa

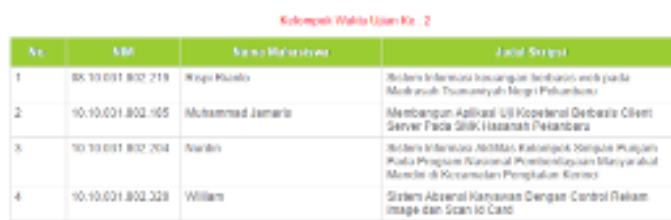

Gambar 14. Kelompok Waktu Ujian Ke-2 untuk 10 Mahasiswa

berosk Waik Uin is :

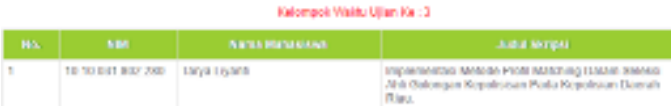

Gambar 15. Kelompok Waktu Ujian Ke-3 untuk 10 Mahasiswa

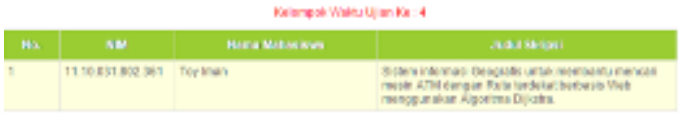

Gambar 16. Kelompok Waktu Ujian Ke-5 untuk 10 Mahasiswa

\section{Pengujian}

Pengujian berikutnya adalah pengujian terhadap 10 mahasiswa peserta ujian. Pada tahapan ini, pengujian dilakukan dengan menguji hasil implementasi dengan hasil perancangan yang telah dilakukan pada bab sebelumnya.
Berdasarkan hasil implementasi, untuk 10 peserta ujian tersebut dapat dikelompokkan menjadi 4 kelompok waktu ujian, hal ini memiliki kecocokan dengan hasil yang diberikan pada tahap perancangan. Namun demikian pengujian yang dilakukan harus dapat mencocokkan keseluruhan peserta ujian untuk setiap kelompok yang dibentuk.

Pada able terlihat bahwa peserta yang termasuk pada kelompok ujian ke 1 adalah mahasiswa dengan NIM 10.10.031.802.076, 08.10.031.802.266, 10.10.031.802.160, dan 10.10.031.802.034. Kelompok ujian ke 1 yang diperlihatkan oleh able memiliki kecocokan dengan hasil implementasi yang diperlihatkan pada gambar hasil implementasi. Hasil pengujian terhadap10 mahasiswa peserta ujian akan diperlihatkan pada table berikut.

Tabel 4. Hasil Perbandingan

\begin{tabular}{|c|c|c|c|}
\hline \multirow{2}{*}{$\begin{array}{c}\text { Kelompo } \\
\text { k Ujian } \\
\text { Ke- }\end{array}$} & \multicolumn{2}{|c|}{ Nomor Induk Mahasiswa (NIM) } & \multirow{2}{*}{$\begin{array}{l}\text { Hasil } \\
\text { Pengujia } \\
\mathrm{n}\end{array}$} \\
\hline & $\begin{array}{c}\text { Hasil } \\
\text { Perancangan }\end{array}$ & $\begin{array}{c}\text { Hasil } \\
\text { Implementasi }\end{array}$ & \\
\hline \multirow{7}{*}{1} & 10.10 .031 .802 .076 & 08.10 .031 .802 .26 & \multirow{7}{*}{ Sama } \\
\hline & 08.10 .031 .802 .266 & 6 & \\
\hline & 10.10 .031 .802 .160 & 10.10 .031 .802 .03 & \\
\hline & 10.10 .031 .802 .034 & $\begin{array}{c}4 \\
10.10 .031 .802 .07\end{array}$ & \\
\hline & & 6 & \\
\hline & & 10.10 .031 .802 .16 & \\
\hline & & 0 & \\
\hline \multirow{8}{*}{2} & 10.10 .031 .802 .204 & 08.10 .031 .802 .21 & \multirow{8}{*}{ Sama } \\
\hline & 10.10 .031 .802 .185 & 9 & \\
\hline & 10.10 .031 .802 .320 & 10.10 .031 .802 .18 & \\
\hline & 08.10 .031 .802 .219 & 5 & \\
\hline & & 10.10 .031 .802 .20 & \\
\hline & & 4 & \\
\hline & & 10.10 .031 .802 .32 & \\
\hline & & 0 & \\
\hline 3 & 10.10 .031 .802 .280 & $\begin{array}{c}10.10 .031 .802 .28 \\
0\end{array}$ & Sama \\
\hline 4 & 11.10 .031 .802 .361 & 11.10 .031 .802 .36 & Sama \\
\hline
\end{tabular}


1

Tabel di atas menjelaskan bahwa hasil implementasi yang dikerjakan komputer dengan menggunakan algoritma Welch-powell dengan hasil perancangan yang dilakukan secara manual (secara visual) memberikan hasil pengujian yang sama, artinya tidak ada perbedaan antara hasil perancangan dan hasil implementasi.

Jika diperhatikan dengan teliti bahwa urutan Nomor Induk Mahasiswa (NIM) pada hasil perancangan tidak sama dengan yang diberikan oleh hasil implementasi, namun demikian perbedaan tersebut tidak dianggap sebagai perbedaan hasil. Hasil pengujian dikatakan berbeda apabila ditemukan mahasiswa yang ujian pada kelompok berbeda antara hasil pengujian dan hali perancangan.

\section{KESIMPULAN}

Setelah dilakukannya perancangan, implementasi serta pengujian untuk membentuk jadwal ujian skripsi dengan teknik pewarnaan simpul graf menggunakan algoritma Welch-powell, maka dapat diberikan kesimpulan:

1. Algoritma Welch-powell yang digunakan pada penelitian ini merupakan algoritma yang telah dimodifikasi.

2. Teknik pewarnaan simpul graf dengan menggunakan algoritma Welch-powell yang telah dimodifikasi dapat diterapkan dalam pembentukan jadwal ujian skripsi di STMIK Amik Riau.

\section{DAFTAR PUSTAKA}

[1]. Agus Susiloputro, Rochmad, dan Alamsyah “ Penerapan Pewarnaan Graf
Pada Penjadwalan Ujian Menggunakan Algoritma Welsh Powell" UNNES Journal of Mathematics, UJM, 2012.

[2].Dedi Masyoyo "Analisa Dan Implementasi Algoritma Priority Dispatching Dalam Penjadwalan Pembagian Ruangan Ujian" Informasi dan Teknologi Ilmiah Vol 2 No 2, Februari 2014.

[3].Imelda Lumbantoruan "Perancangan Aplikasi Penjadwalan Bimbingan Belajar Dina Education Center Menggunakan Metode Welch-Powell." Pelita Informatika Budi Darma Vol 7 No 2, Agustus 2014

[4].Koko Harianto, T. Sy. Eiva Fatdha "Penerapan Pewarnaan Simpul Graf Untuk Menentukan Jadwal Ujian Skripsi Pada STMIK-AMIK Riau Menggunakan Algoritma Welch-Powell” SATIN Vol 1 No 2, 2015.

[5].Rahmat Januar Noor, Hasmawati dan Hendra " Implementation of Sequent Algorithm in Coloring Vertex on Simple Graph.”, MANASIR Vol 1 No 1 Hal 1922, 2013.

[6].Rinaldi Munir "Matematika Diskrit Revisi Kelima" Bandung : Informatika, 2012.

[7].Riwinoto, R. Yogo Kartono Isal "Simulasi Optimasi Pengaturan Lampu Lalu Lintas Di Kota Depok Dengan Menggunakan Pendekatan Greedy Berbasis Graf' Seminar Nasional Sistem dan Informatika 2010, Bali, November 2010 .

[8].Setia Astuti "Penyusunan Jadwal Ujian Mata Kuliah Dengan Algoritma Pewarnaan Graf Welch Powell" Jurnal Dian Vol 11 No 1, Januari, 2011. 